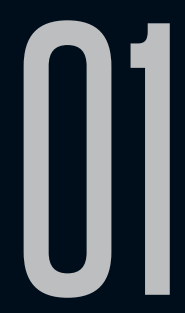

\title{
TRIBUTE TO H.P. LOVECRAFT ADMIRÁVEL MUNDO NOVO
}

Leonardo Vidal

Recebido em 06 mar 2017. Doutorando em Literaturas de Língua Inglesa Aprovado em 07 mar 2017. pelo Programa de Pós-Graduação em Letras da Universidade Federal do Rio Grande do Sul (UFRGS). Mestre em Letras/Literaturas Estrangeiras Modernas/ Literaturas de Língua Inglesa pela Universidade Federal do Rio Grande do Sul (2014). Licenciado em Letras/Inglês pela Universidade do Vale do Rio dos Sinos (2010) e bacharel em Comunicação Social/ Jornalismo pela Universidade do Vale do Rio dos Sinos (2009). Vencedor do Troféu HQMix de 2011 na categoria TCC. Quadrinista e ilustrador. 
Iribute to

(1) (1)

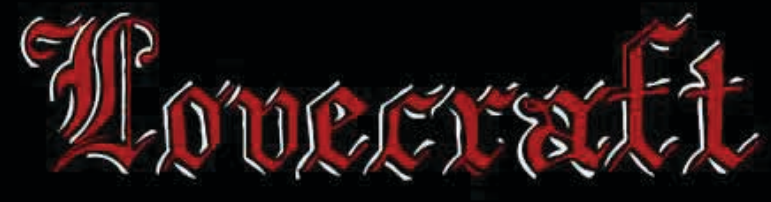

Admiravel Mundo Novo

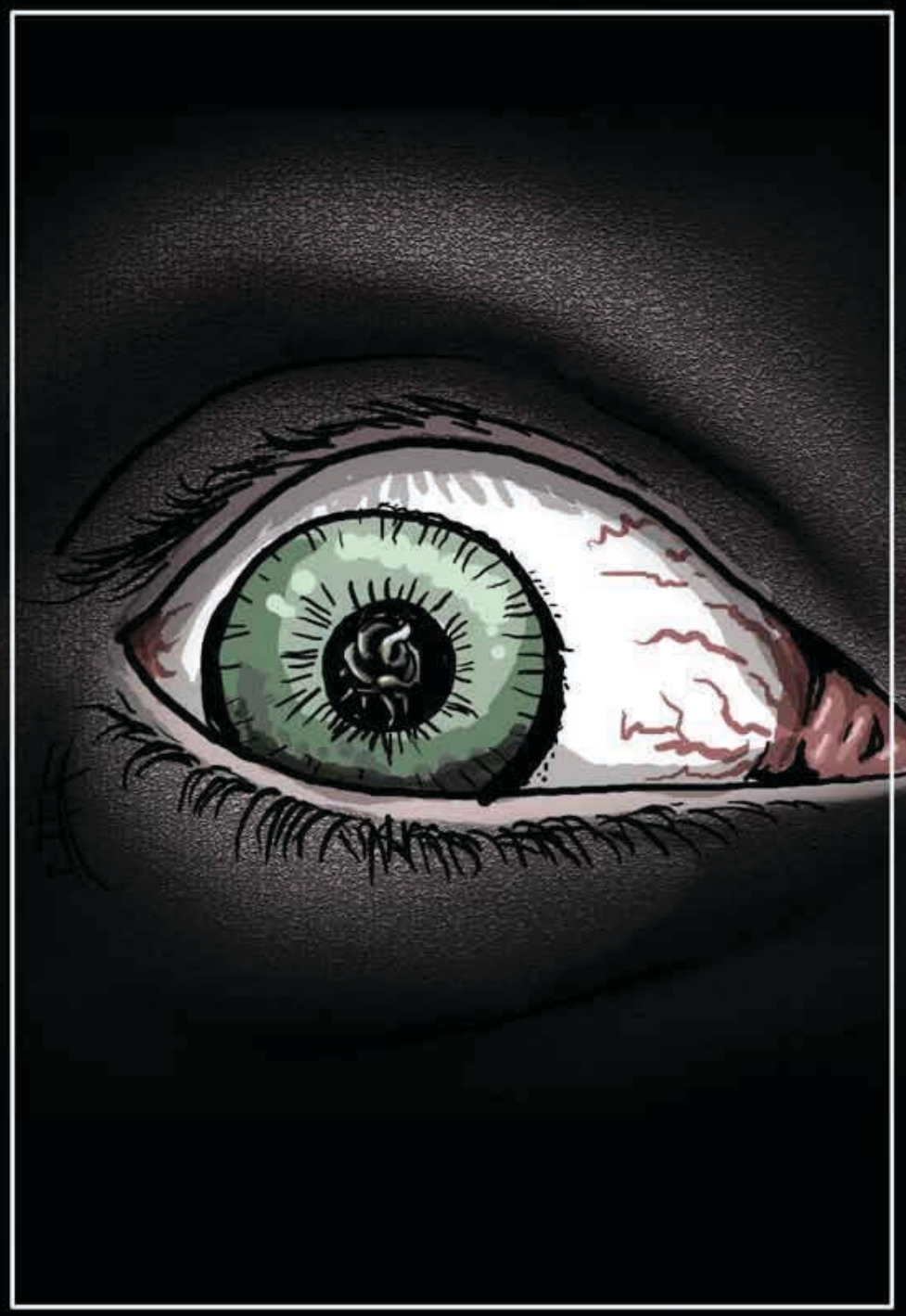

[eonardo Vidal 

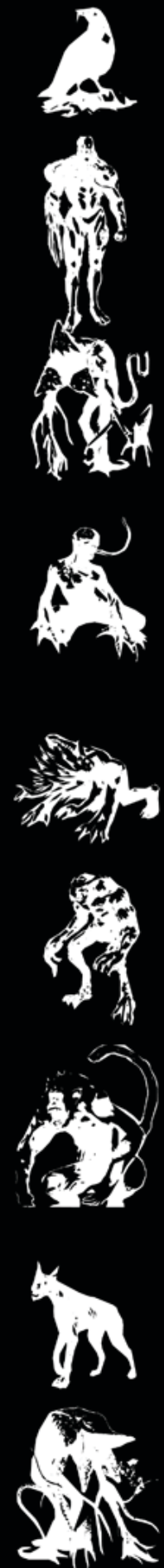

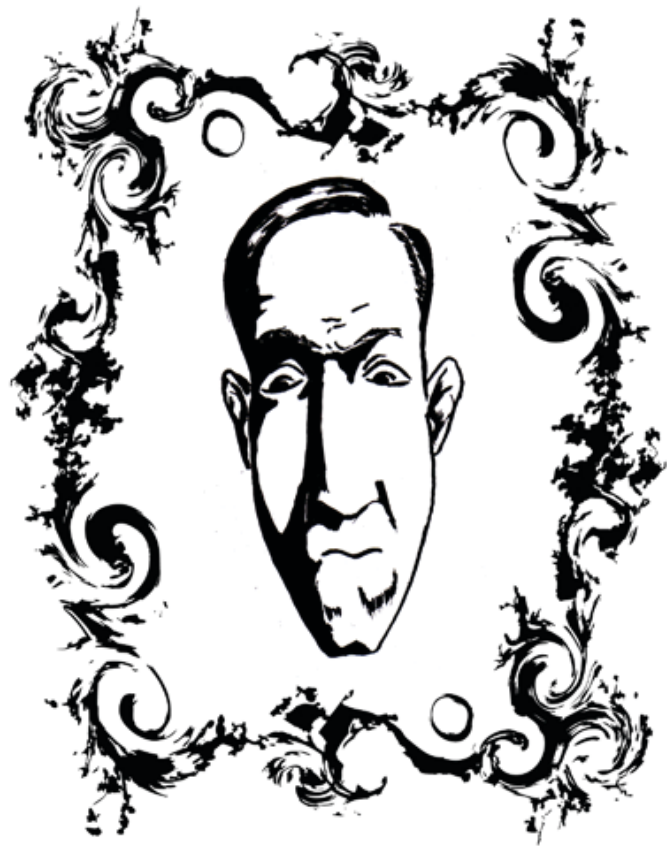

Howard Phyllis Lovecraft foi um de meus companheiros de infância.

Desde muito cedo comecei a apreciar contos de horror e mistério, e H.

P. Lovecraft é um dos mestres do gênero, como Edgar Alan Poe, Ambrose Bierce, Conan Doyle (embora este tenha ficado mais famoso como o criador de Sherlock Holmes), Defoe, Maupassant, entre outros.

Todos esses eram amigos. Mas Lovecraft sempre foi especial.

O problema é que com Lovecraft, muito do horror está nas sombras. No que não se vê, no que não se sabe, e de que só se pode intuir que não é nada de bom. Algo tão danoso e incompreensivel que frequentemente leva à loucura os que se aventuram a tentar desvendar seu mistério. Conforme o próprio autor, no livro O Horror Sobrenatural na Literatura, "o verdadeiro conto de horror tem algo mais que sacrificios secretos, ossos ensanguentados ou formas amortalhadas fazendo tinir correntes em concordância com as regras. Há que estar presente uma certa atmosfera de terror sufocante e inexplicável ante forças externas

ignotas; e tem que haver uma alusão, expressa com a solenidade $e$ seriedade adequada ao tema, à mais terrivel concepçâo da inteligência humana - uma suspensão ou derrogação particular das imutáveis leis da natureza, que são nossa única defesa contra as agressỏes do caos $e$ dos demônios do espaço insondado."

$\mathrm{E}$ as pessoas ainda me perguntam por que eu gosto do trabalho dele.

Esse preciosismo de linguagem, a seriedade com que trata o tema, sua preocupação em criar o clima do conto e erguê-lo em um crescendo, conduzindo o leitor ao horrivel desfecho, quase não têm pares no universo da literatura de horror.

Esse quadrinho é uma homenagem a um velho amigo. Nele, tentei colocar tantos elementos de sua ficção quanto pude. Às vezes pontualmente, às vezes de modo desastrado. Principalmente, tentei colocar no papel as criaturas que seus contos me levaram a imaginar, ao longo dos anos. Sei que há muitos desenhistas mais habilidosos que eu capazes de mais. Também sei que há fãs mais apaixonados.

Mas é algo que havia me prometido fazer algum dia, e que veio à tona agora, dessa forma que ai está. O leitor verá que a "receita" lovecraftiana para escrever um conto de horror é respeitada, aqui. E mais não falo, para não estragar o prazer da leitura. Se houver leitura, se hou-
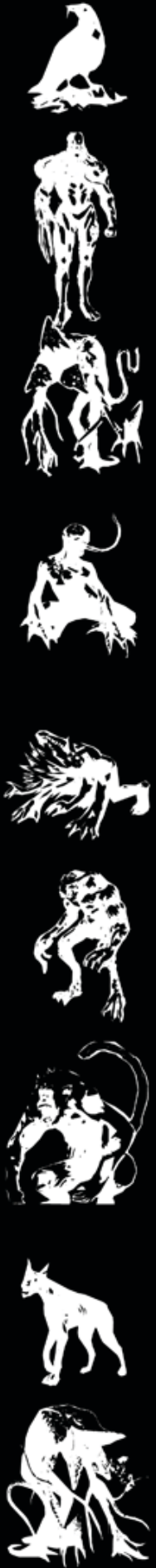

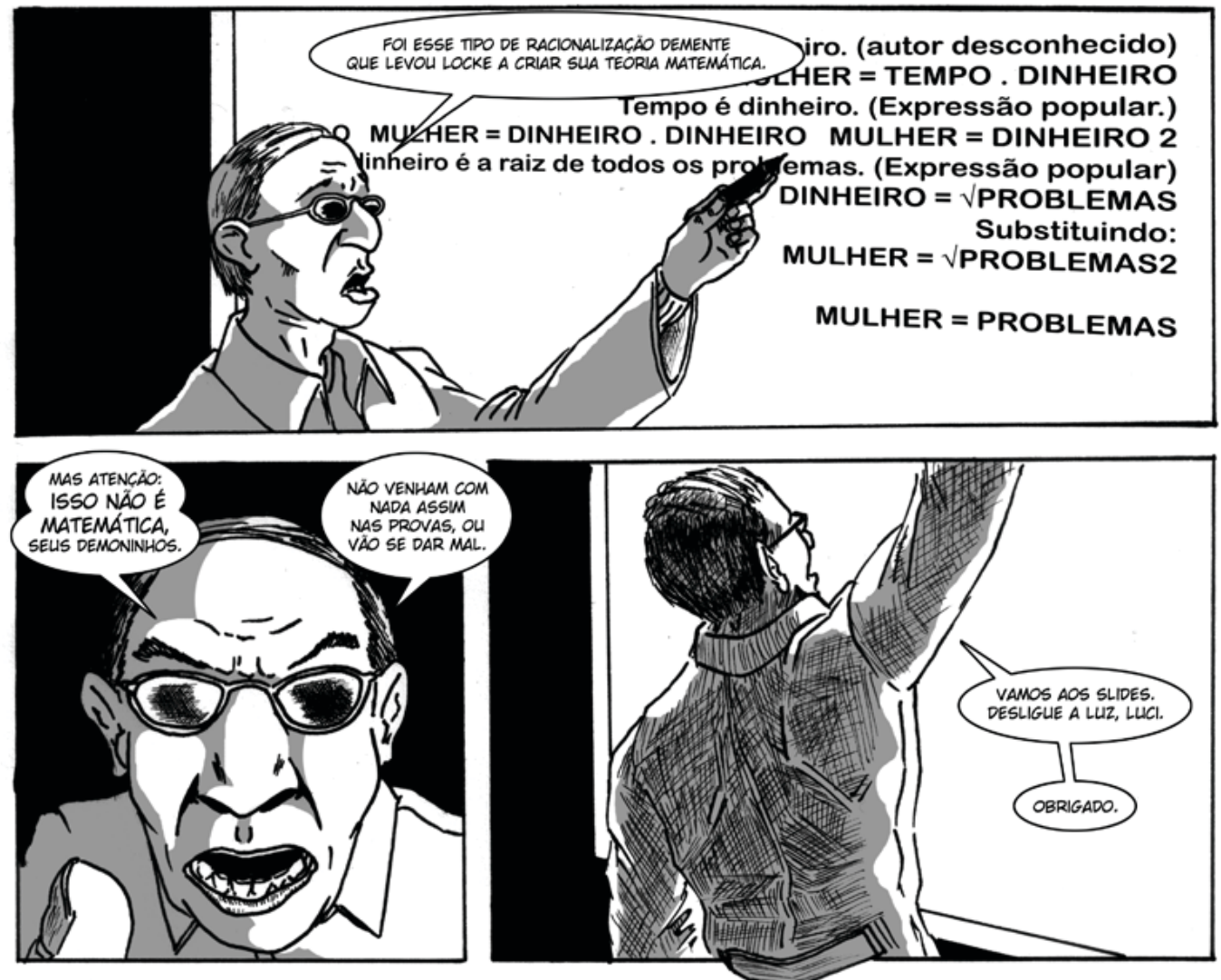

ESSE E RAFAEL LOCKE. ELE E O RESPONSÁVEL PELA DESCOBERTA DO FOSSO DAS DIMENSOES, E PAI DA MAIOR PARTE DOS AVANCOS DA NOVA MATEMÁTICA.

UMA DAS MALRES MENTES DA CIENCLA MODERNA.

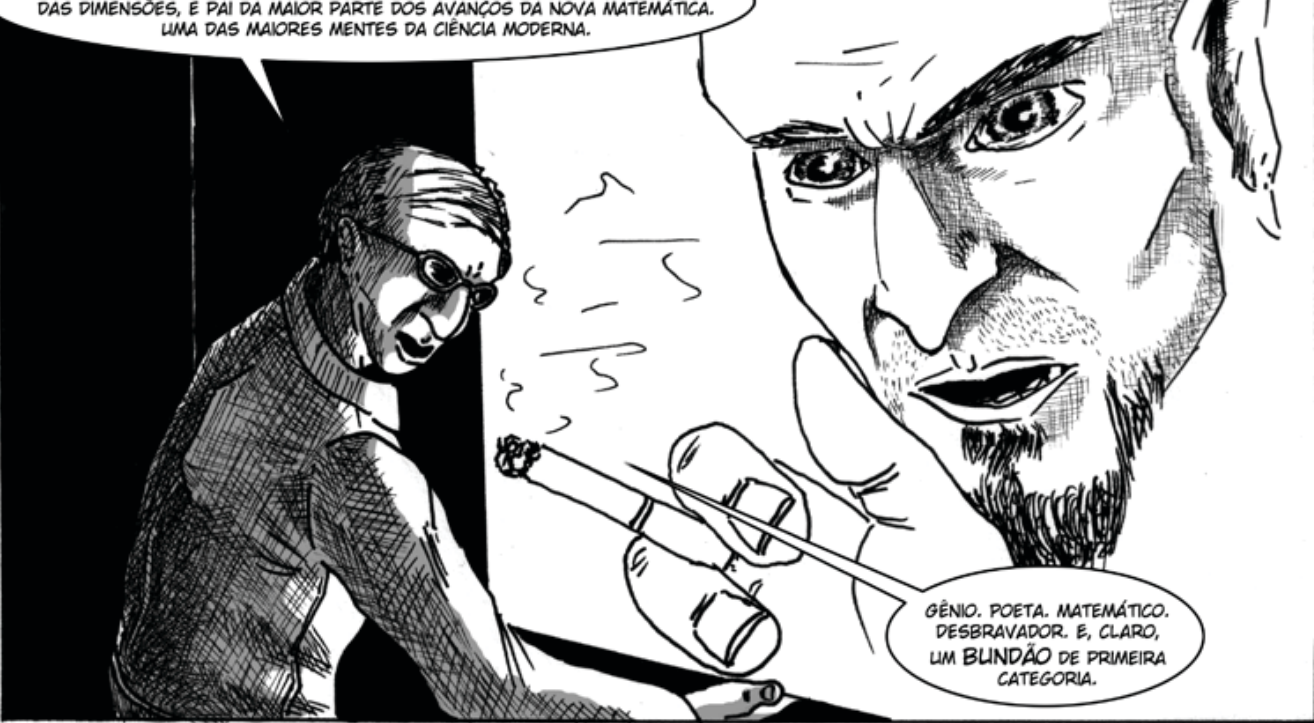




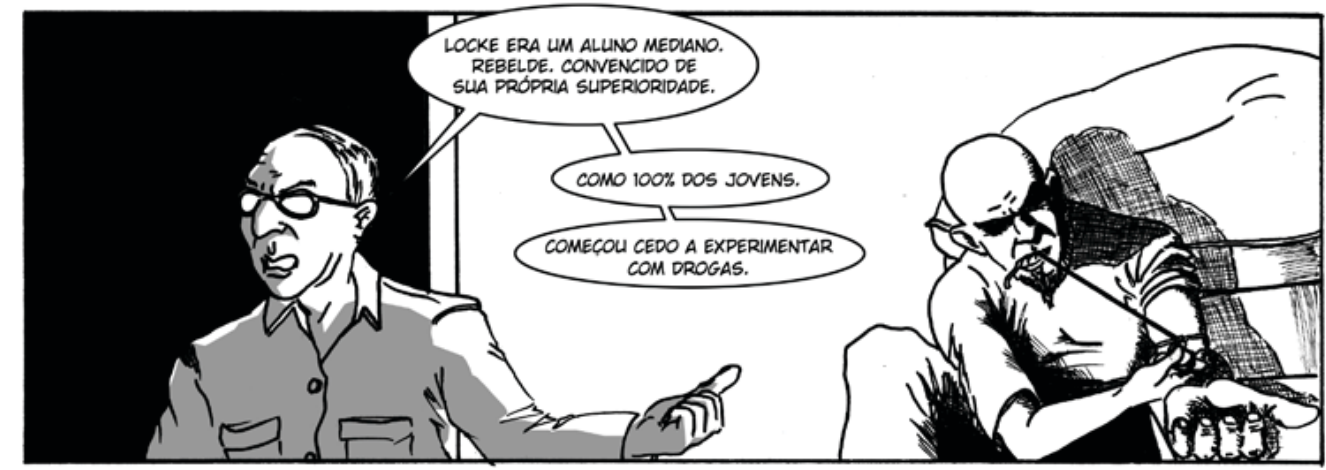

E ESTRANHO QUE UMA MENTE TÃO BRILHLNTE

TENHA CAIDO EM UMA ARMADILHA TRO

ELI ME PERGUNTO SE.
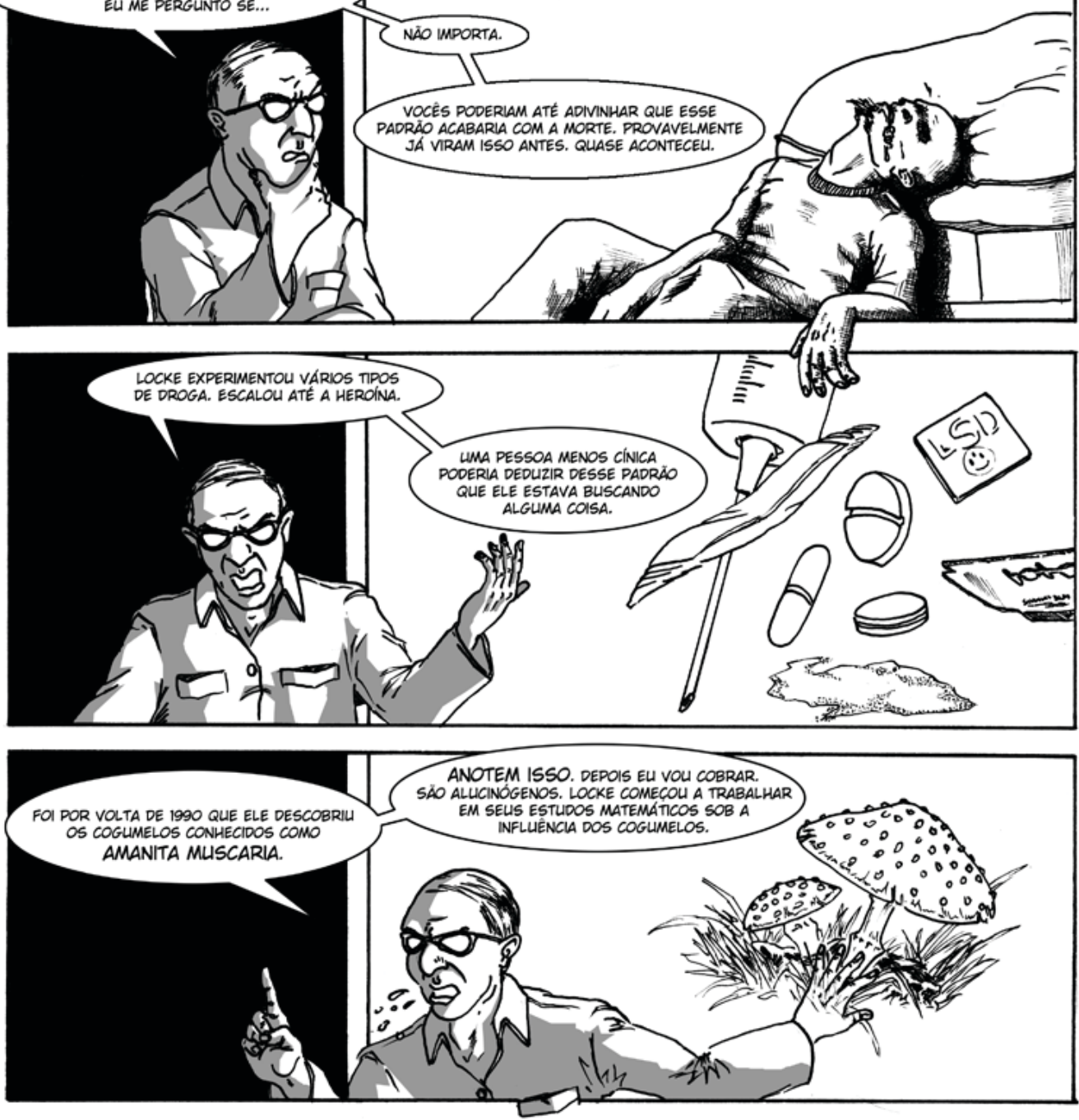

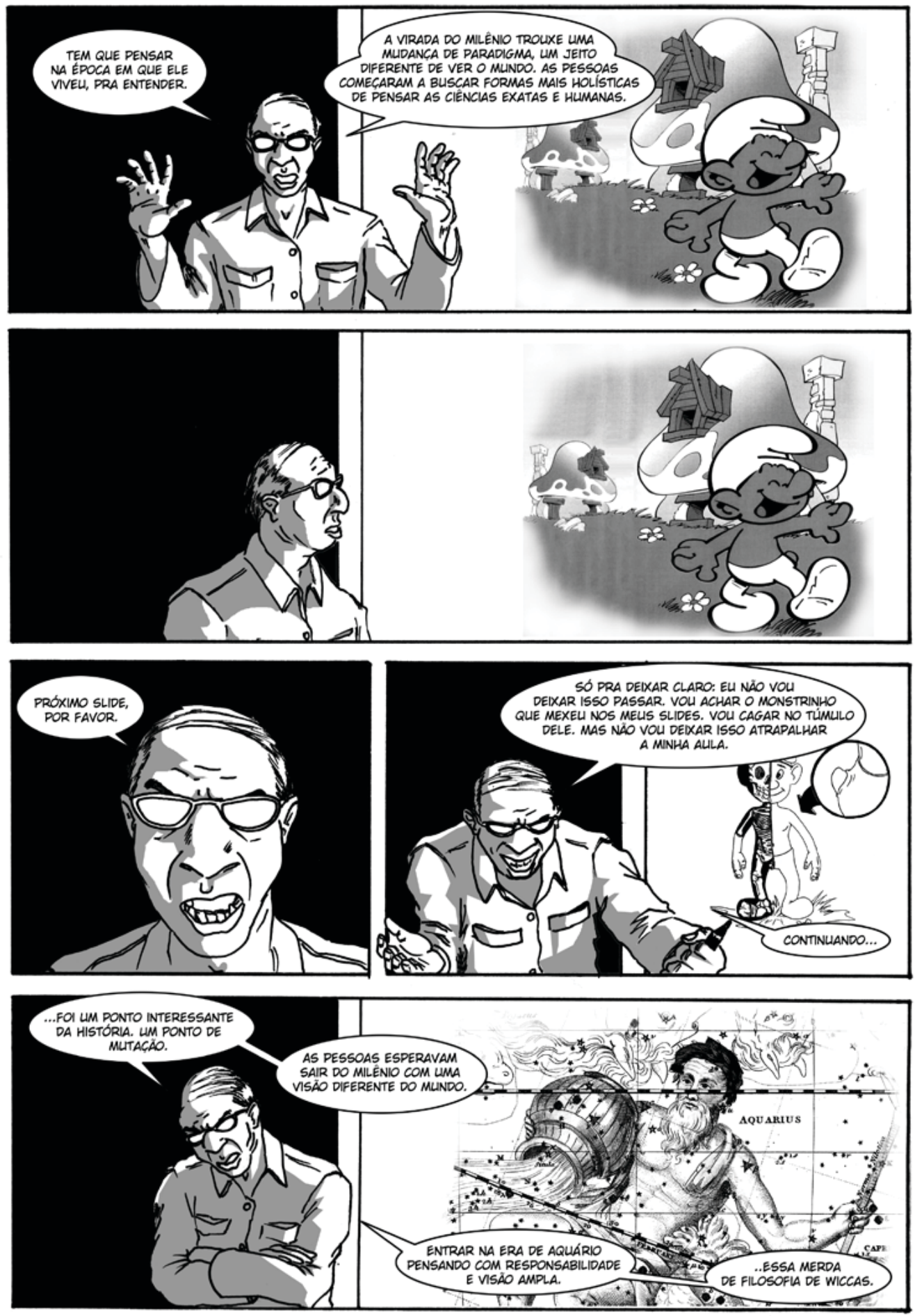

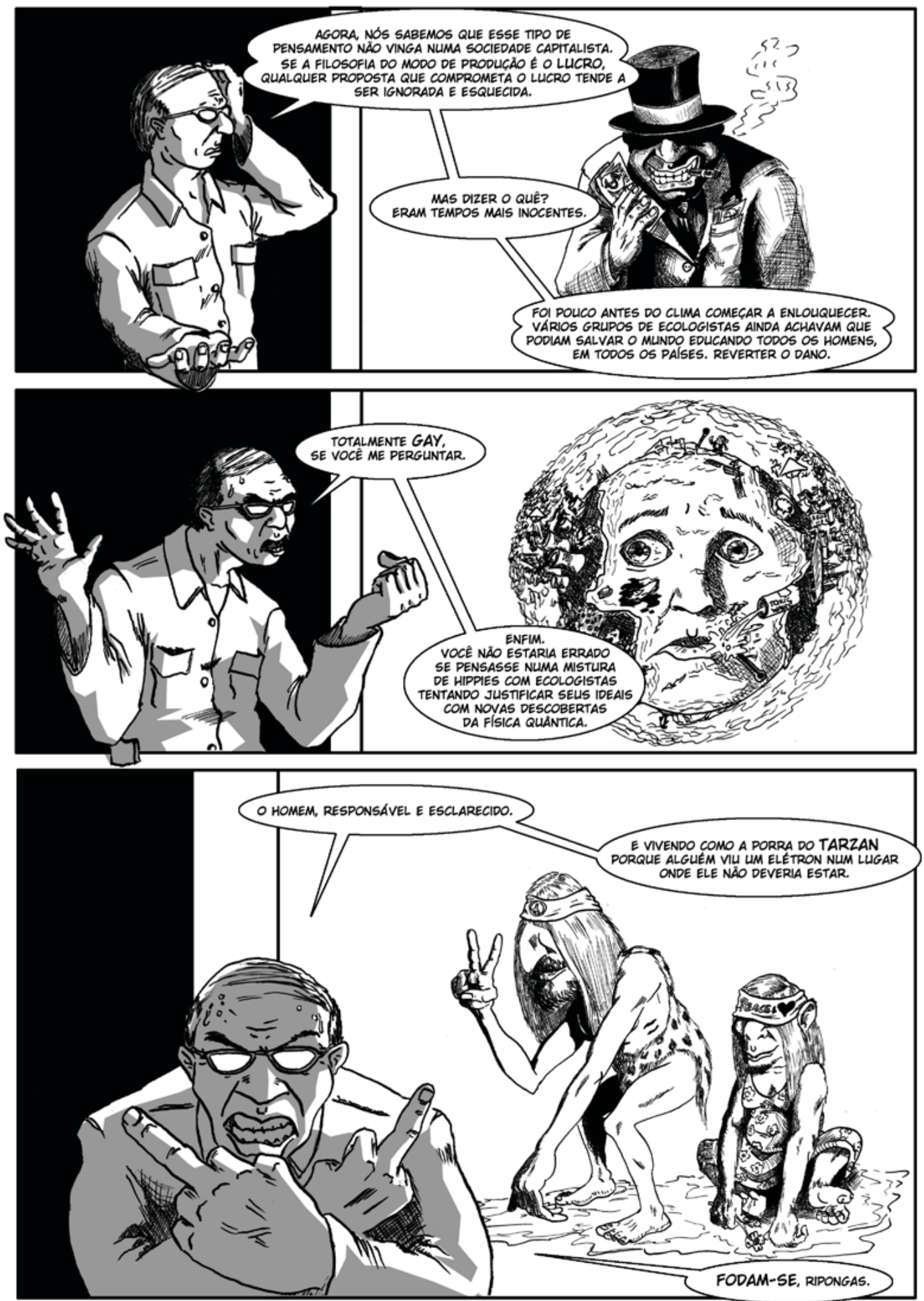
LOCKE CRESCEU COM ISSO,

ESTUDOU CAPRA, VIVEU ESSE TEMPO.

E LIA MUITO, TAMBEM. ADMIRAVA

VARIOS ESCRITORES.

ALDOUS HUXLEY, ANTON WILSON, BAUDELAIRE, CASTANEDA,

BUKOWSKY KEROUAC, RIMBALD, VERLAINE, WILLIAM BURROUGHS.

PRA CITAR ALGUNS. TODOS ESSES CARAS TINHAM ALGO EM COMUM.

TODOS USARAM DROGAS NA PRODUCAOO DE SELS TRABALHOS.
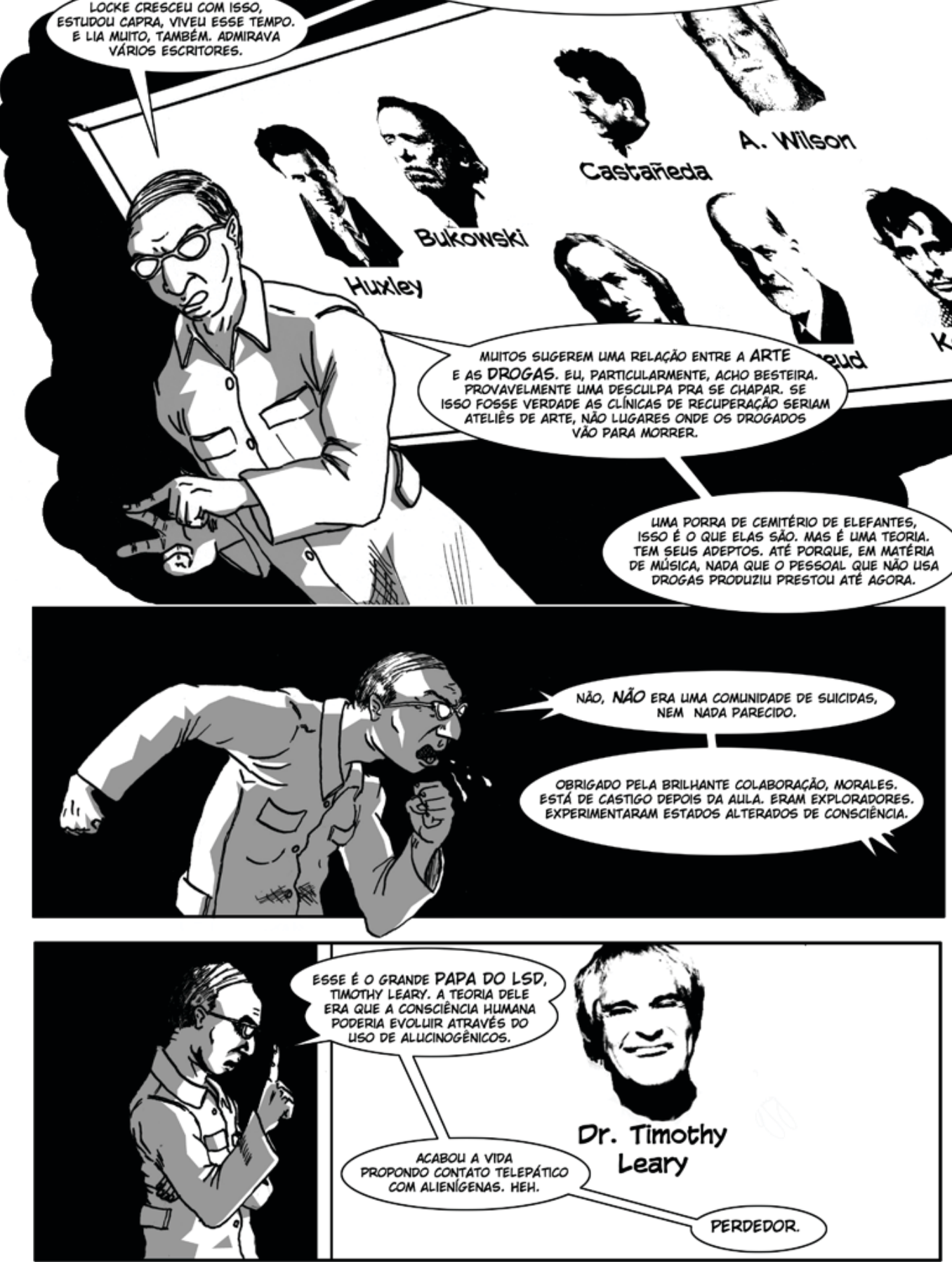


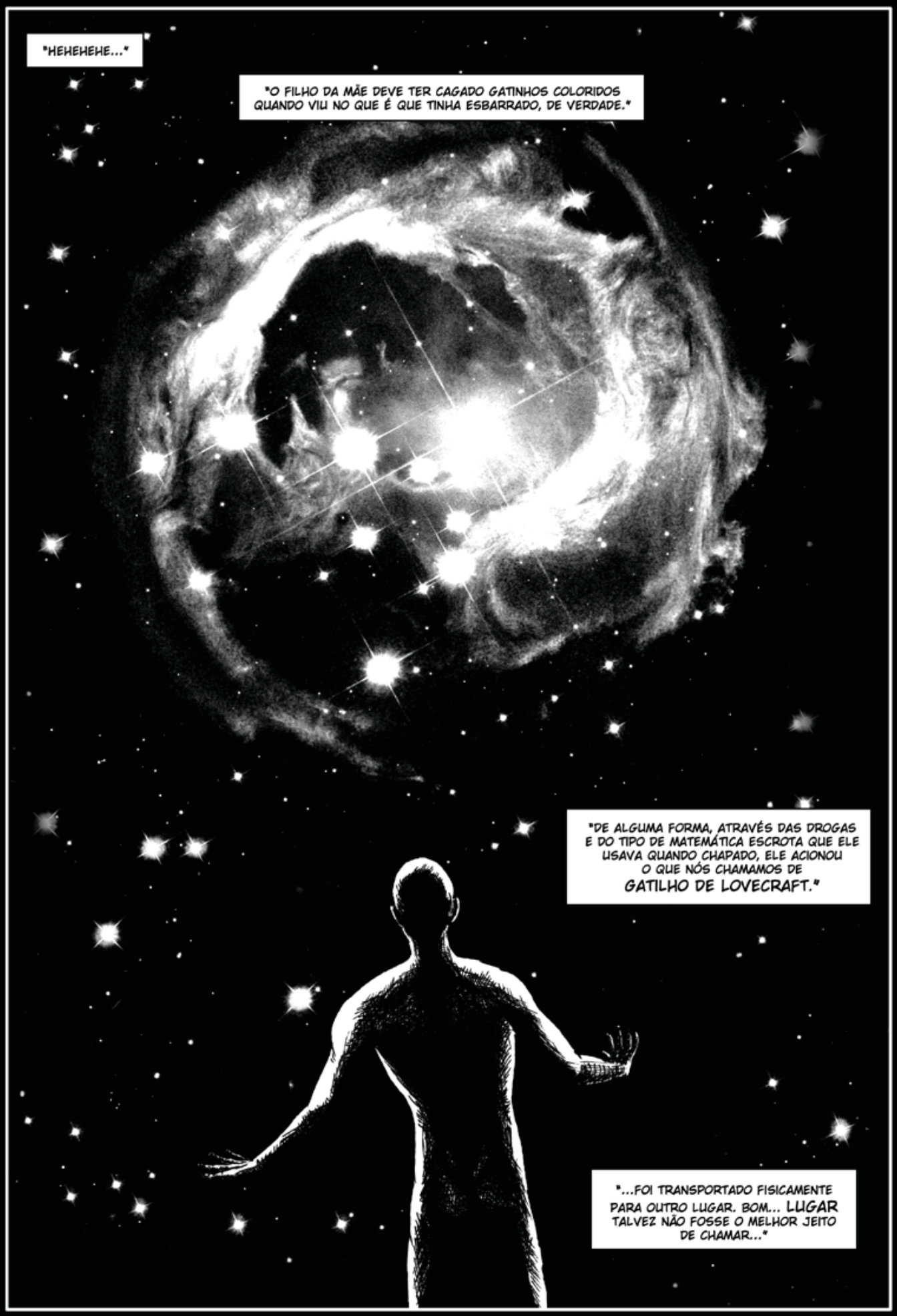



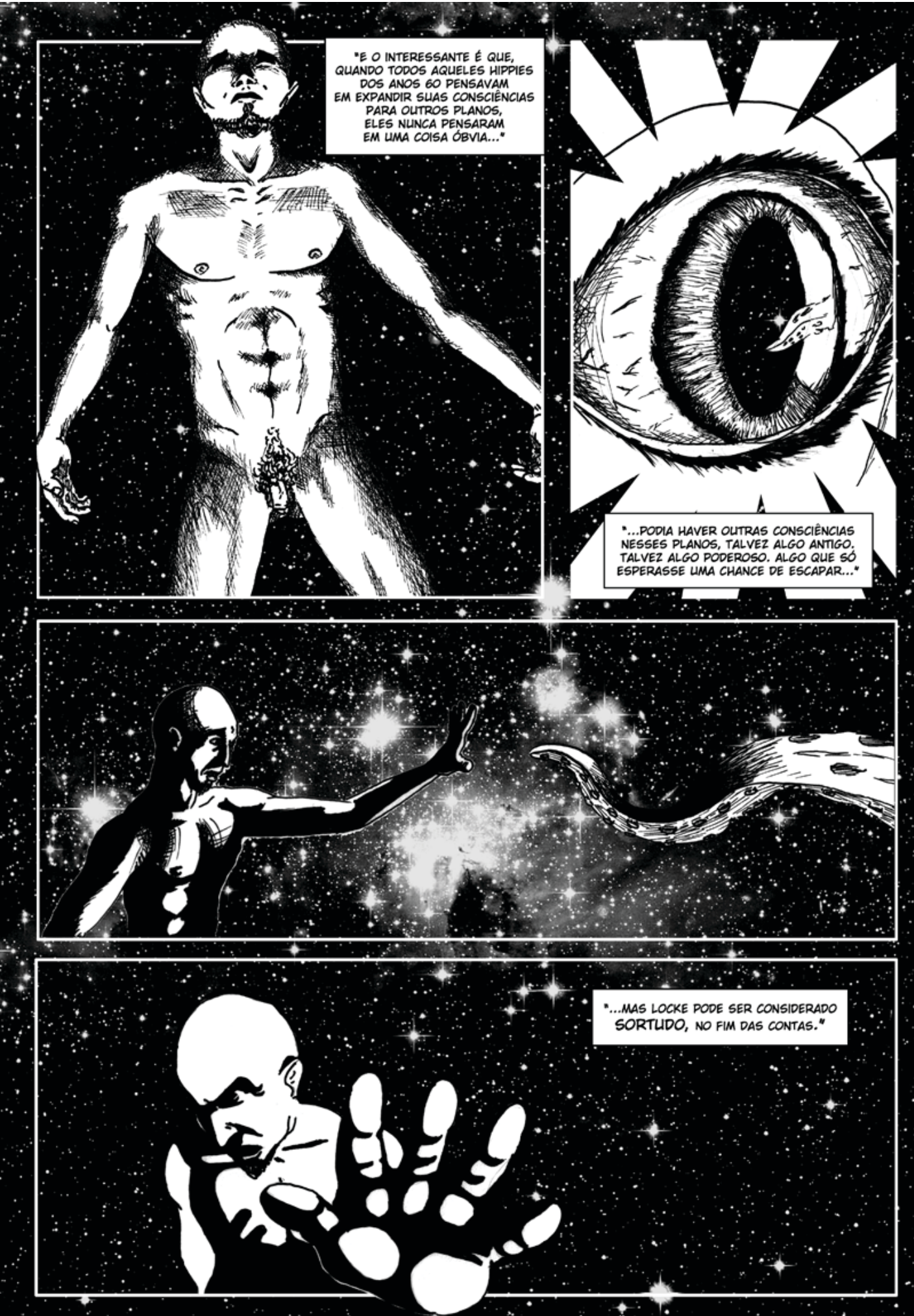

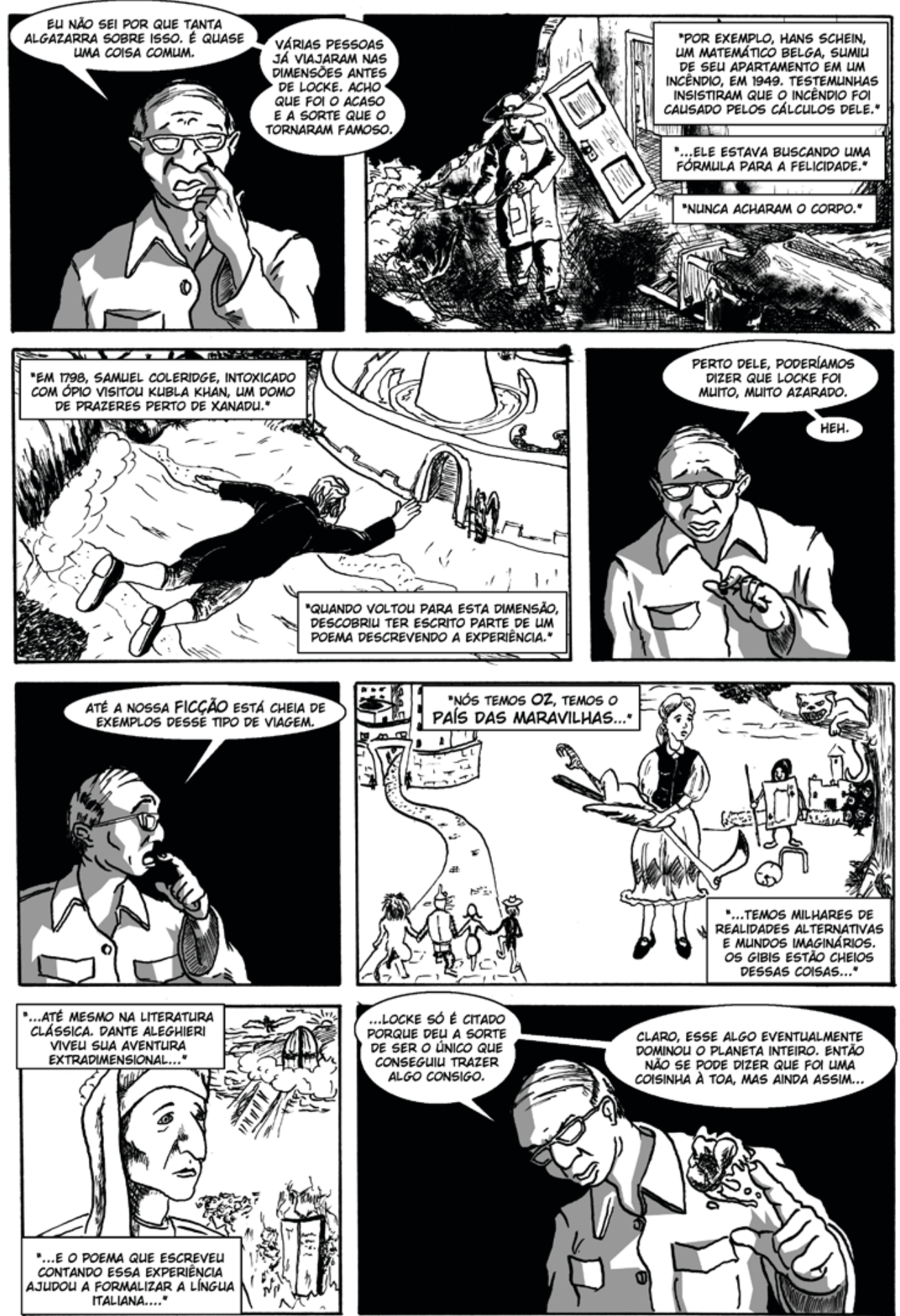

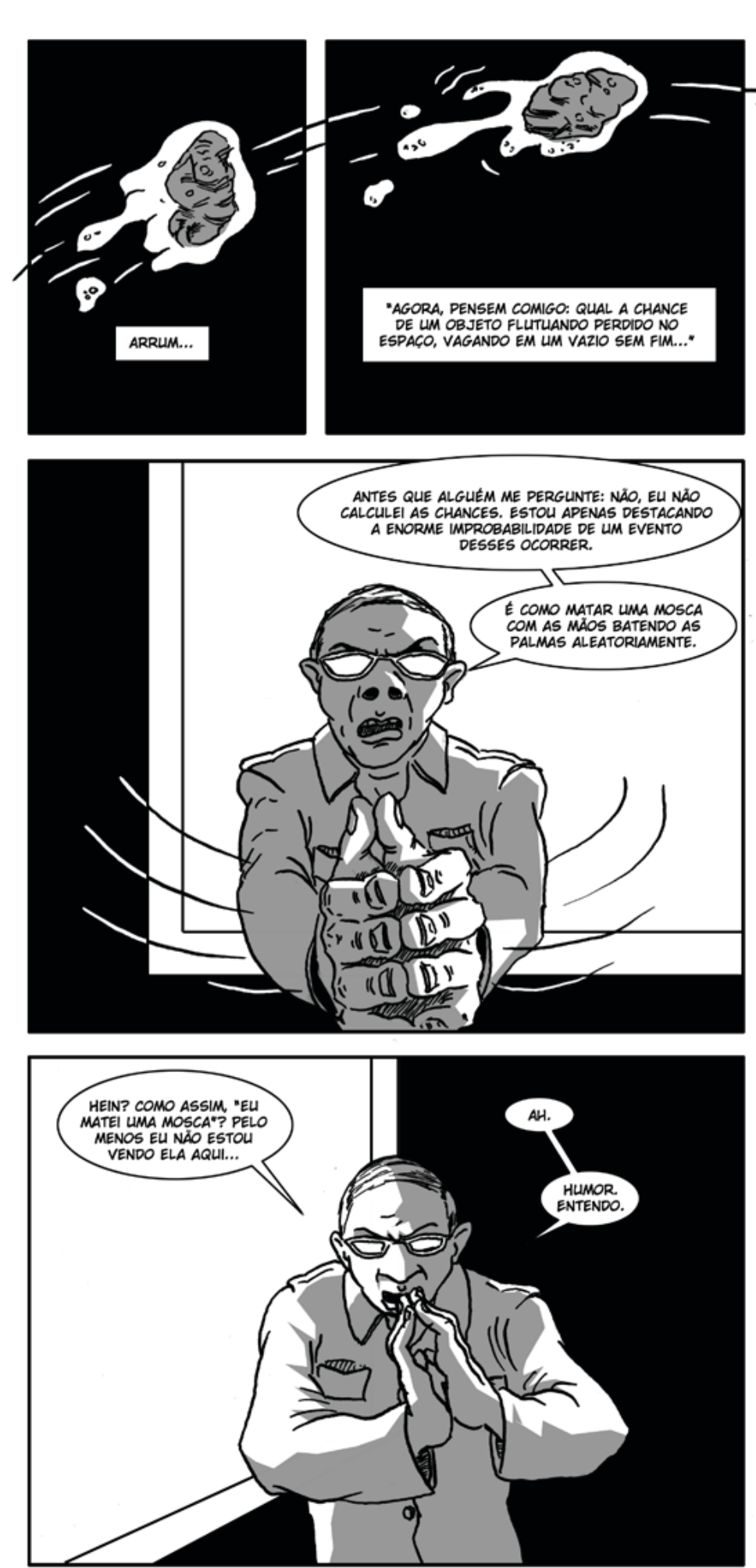

"SEJA COMO FOR, ESSA

FOI A GRANDE SORTE E A GRANDE INFELICIDADE DE LOCKE. QUAASE COMO CAIR NUM POCO E ACHAR UMA MINA DE OURO NO FUNDO. CLARO, SE VOCEE ESTA NO FUNDO DE UM POCO NÄO TEM MUITO USO PRA OURO... MAS E $O$ PRINCÍPIO DA COISA."

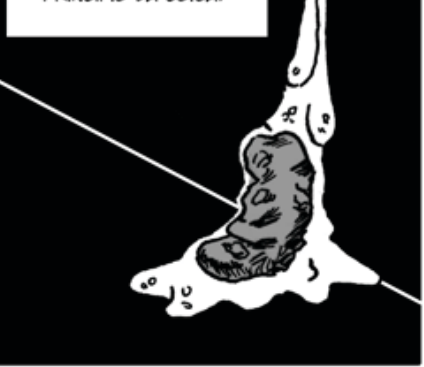


-A PROXIMA COISA QUE SABEMOS DELE E QUE ESTAVA VIVENDO COMO MENDIGO NA CIDADE DE ARKHAM, MASSACHUSSETS, NOS ESTADOS UNIDOS. ISSO E TRES MESES DEPOIS DELE TER DESAPARECIDO DO SEU QUARTO. EU NAO SEI SE MENCIONEI ISSO, MAS LOCKE ERA AUSTRALIANO."
-BOM. ISSO NÃO CHEGA A SER ESTRANHO. FOI SO DEPOIS QUE OS HISTORIADORES SE INTERESSARAM E COMECARAM A NOTAR AS PECLLLIARIDADES DO CASO DELE..."
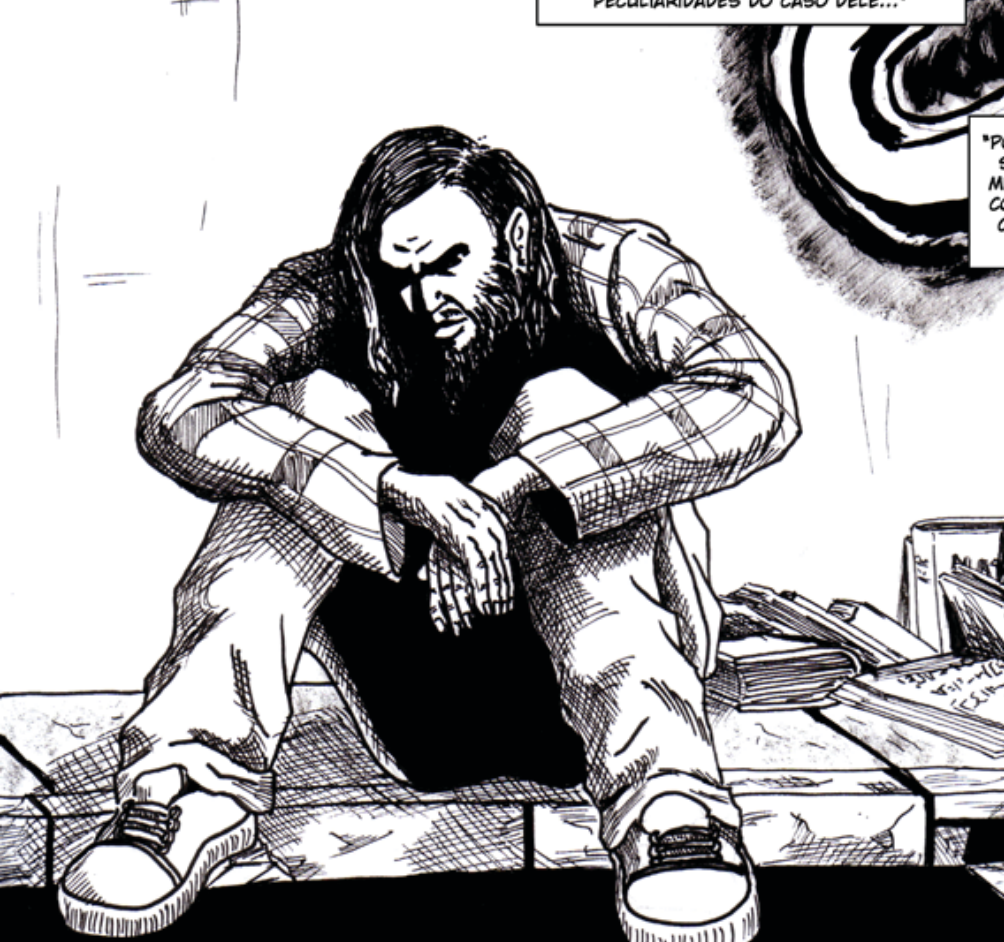

-por exemplo... O cabelo e a barba dele SUGERIRIAM ANOS DE CRESCIMENTO. NAO MEROS TRES MESES. O QUE MUITOS VIRAM

\section{COMO LOURURA, TAMBEM, PARECIA SER UM COMPORTAMENTO SISTEMÁTICO DE CUNHO RELIGIOSO. ESSE TIPO DE COISA." \\ W 7

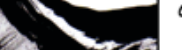



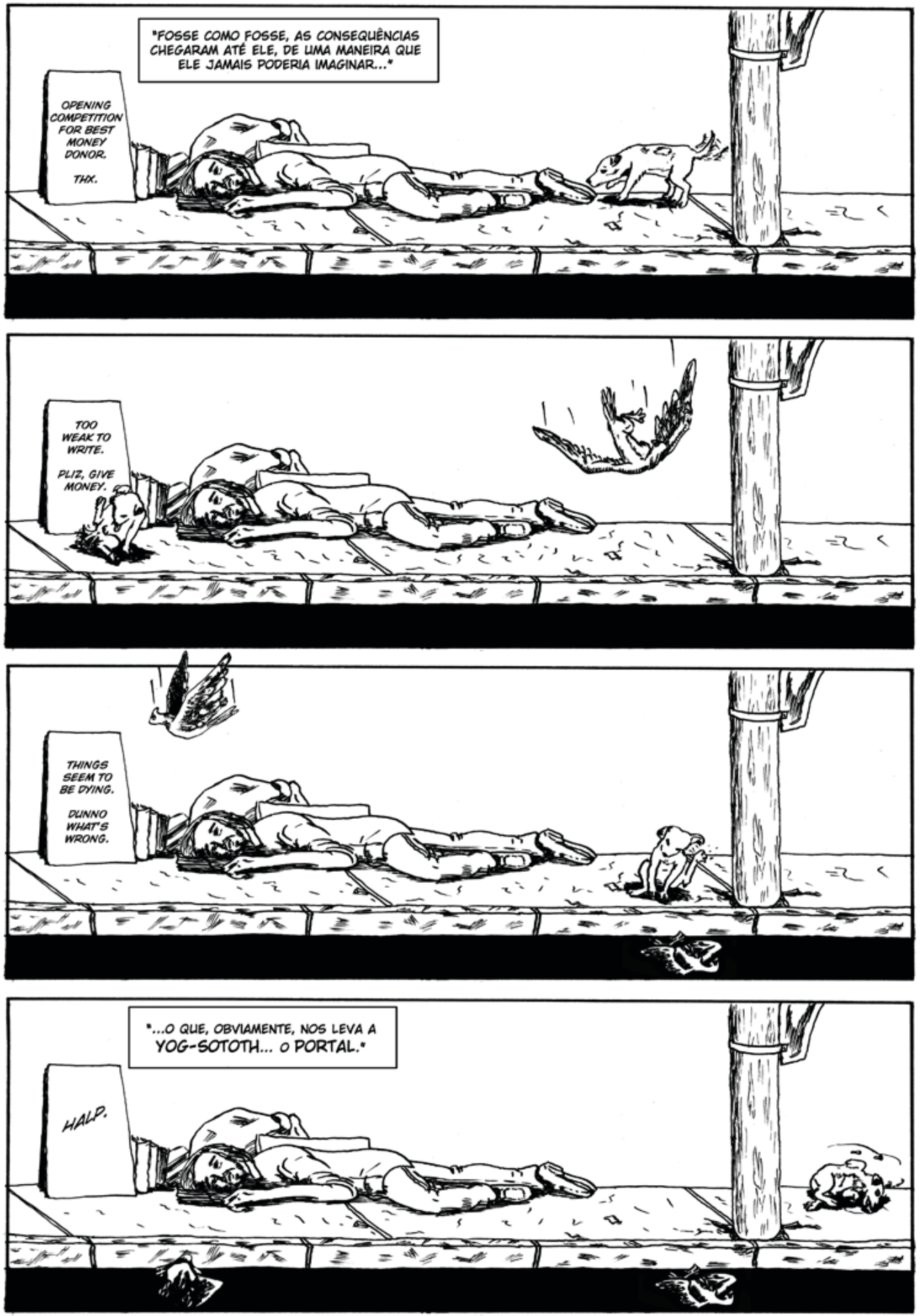
"LOCKE SABIA QUE YOG-SOTOTH ERA A CHAVE PARA A ENTRADA DOS ANTIGOS NESSA REALIDADE. SABLA QUE SUAS INVOCACOES DEVERIAM DESPERTA-LO. $O$

QUE LOCKE NLINCA COMPREENDEU FOI A NATUREZA DE YOG-SOTOTH. A MANEIRA DE SLA VINDA."

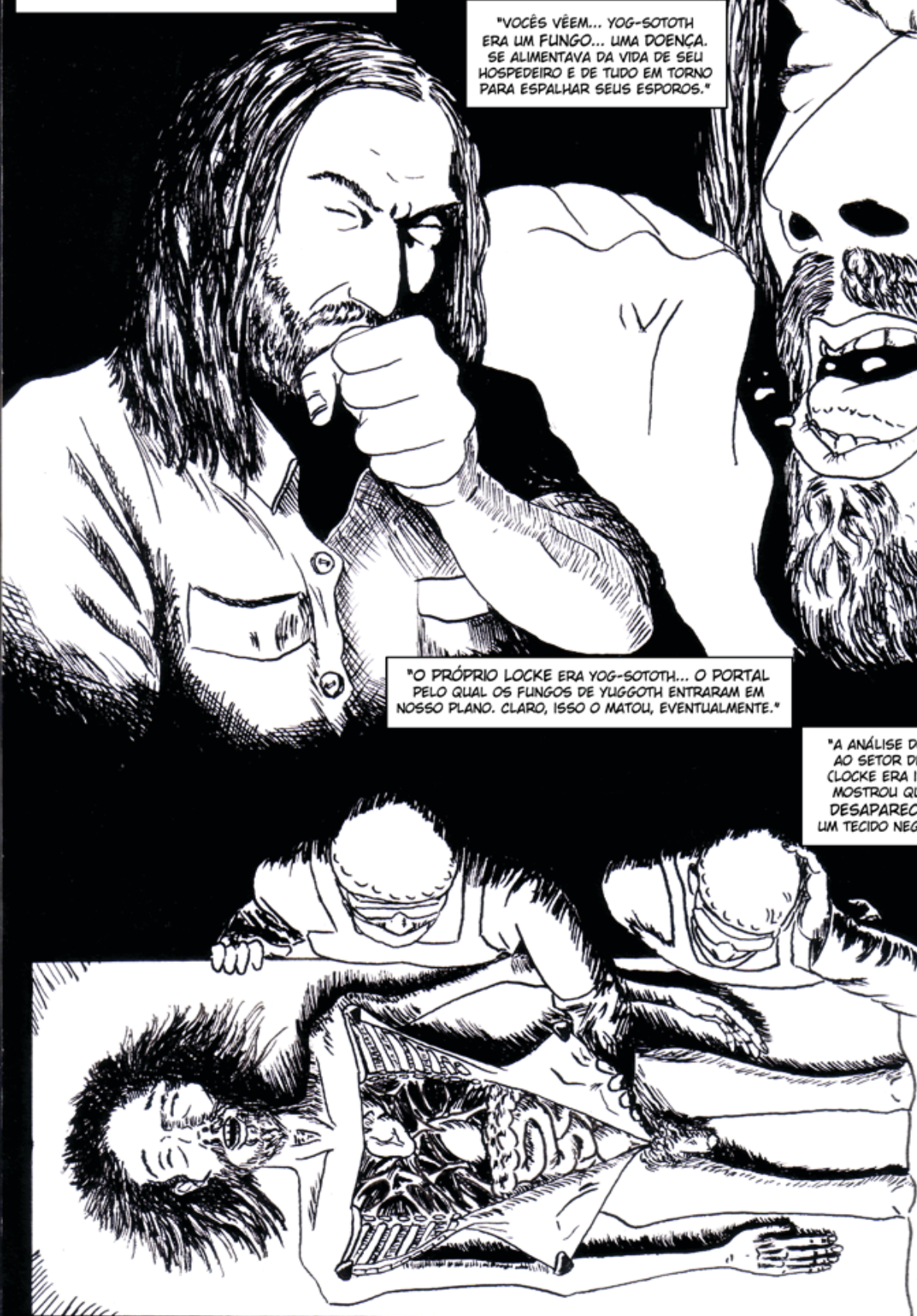

"A ANÁLISE DO CORPO DE LOCKE, DOADO AO SETOR DE MEDICIDA DA MISKATONIC LOCKE ERA INDIGENTE, LEMBREM-SE...) STIROU QUE SELS PULMOES HAVIAM DECIDO. EM SEU LLGAR HAVA 1)

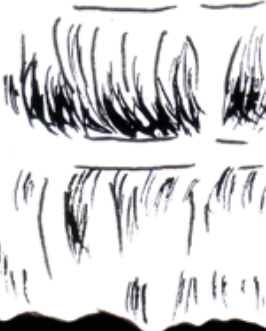



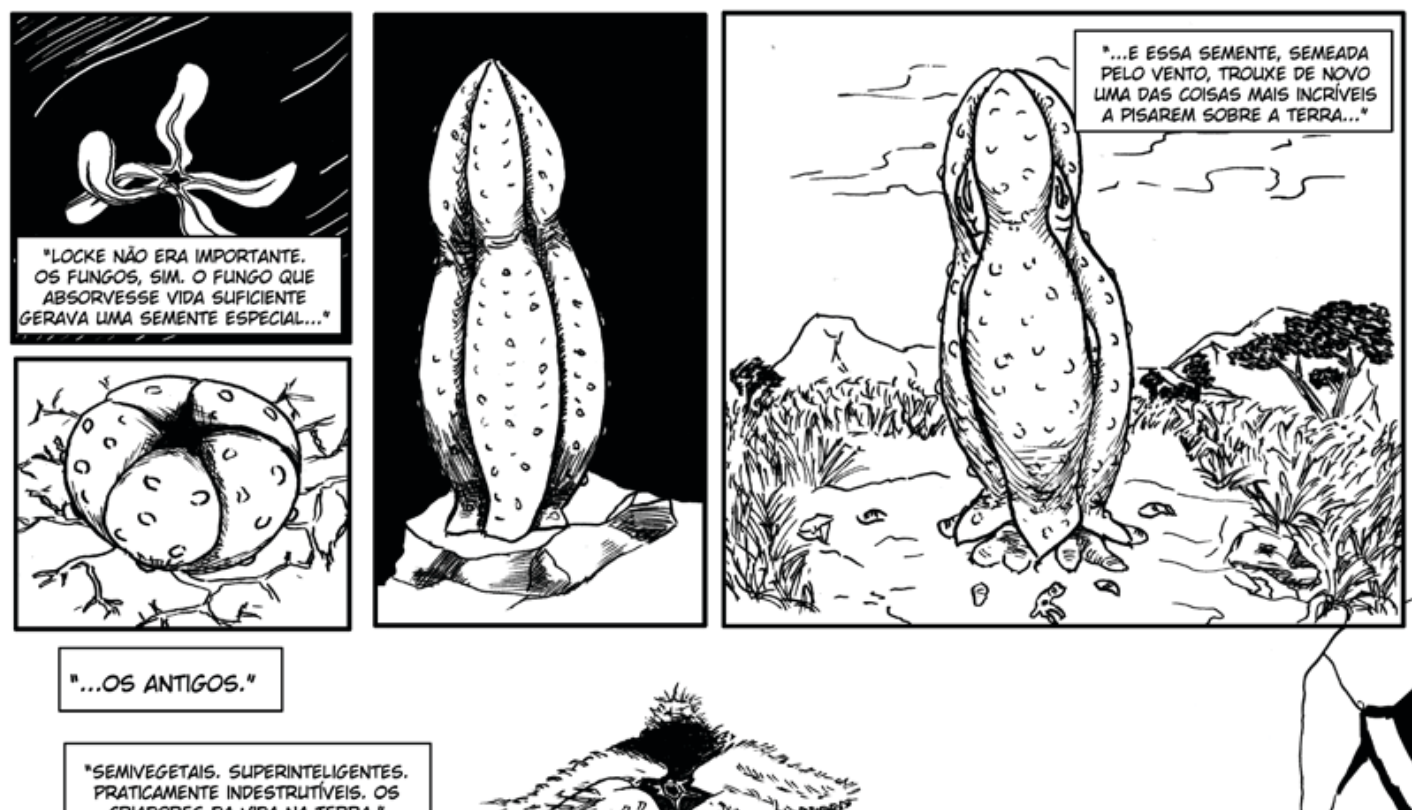

CRIADORES DA VIDA TERRA.

\section{"RENASCIDOS ENTRE NÓS GRACAS A LOCKE, SEUS MOTIVOS E ATOS CONTINLLAM UM ENIGMA. NAOO ENTENDEMOS SULA LINGUA MUSICAL NEM SLAA FISIOLOGLA ALIENIGENA. NAO ENTENDEMOS SELSS ATOS OU SULA FILOSOFLA. NOSSAS NOCDES DE ANTROPOLOGIA OU CULTURA NÄO SE APLICAM."}



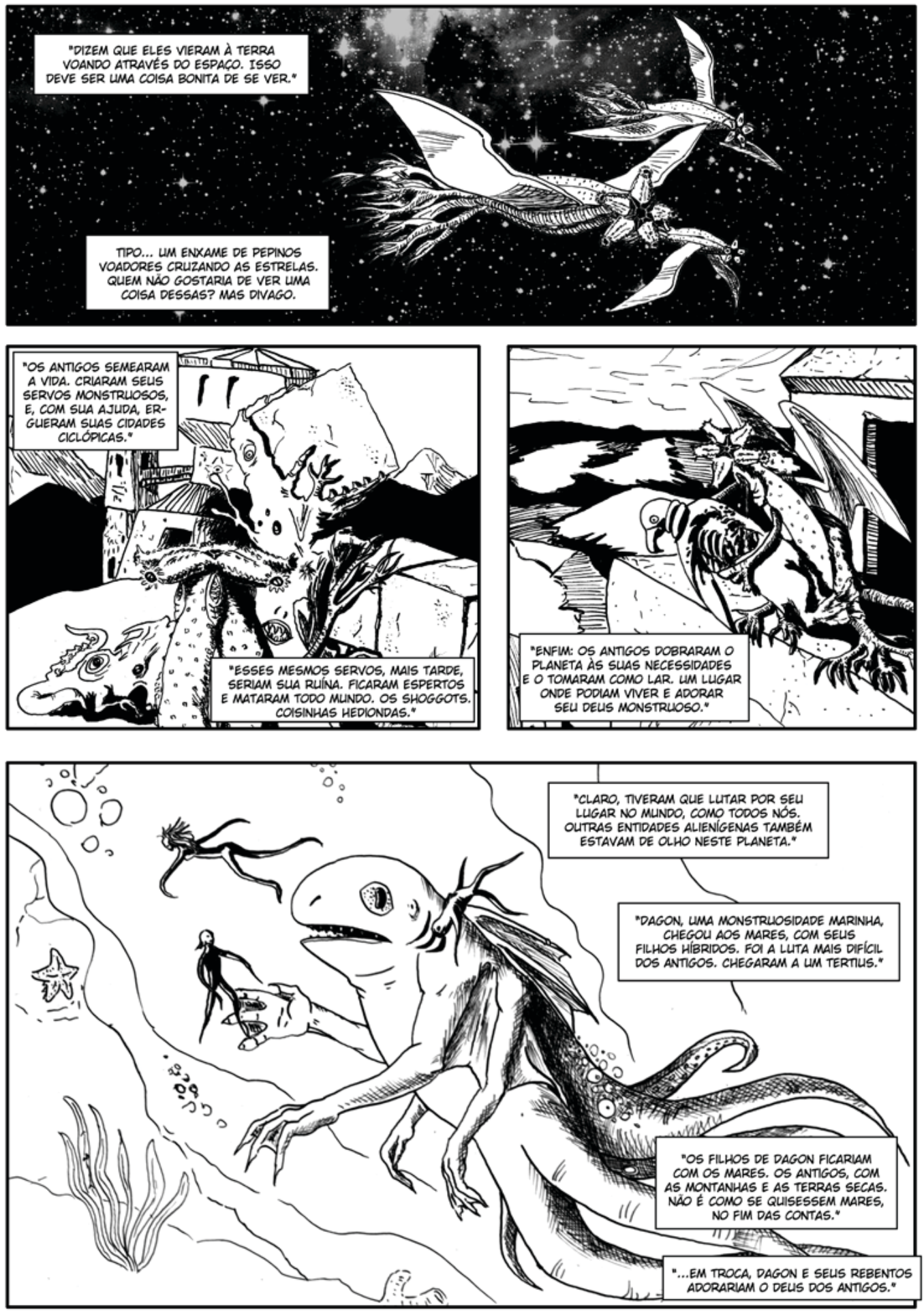

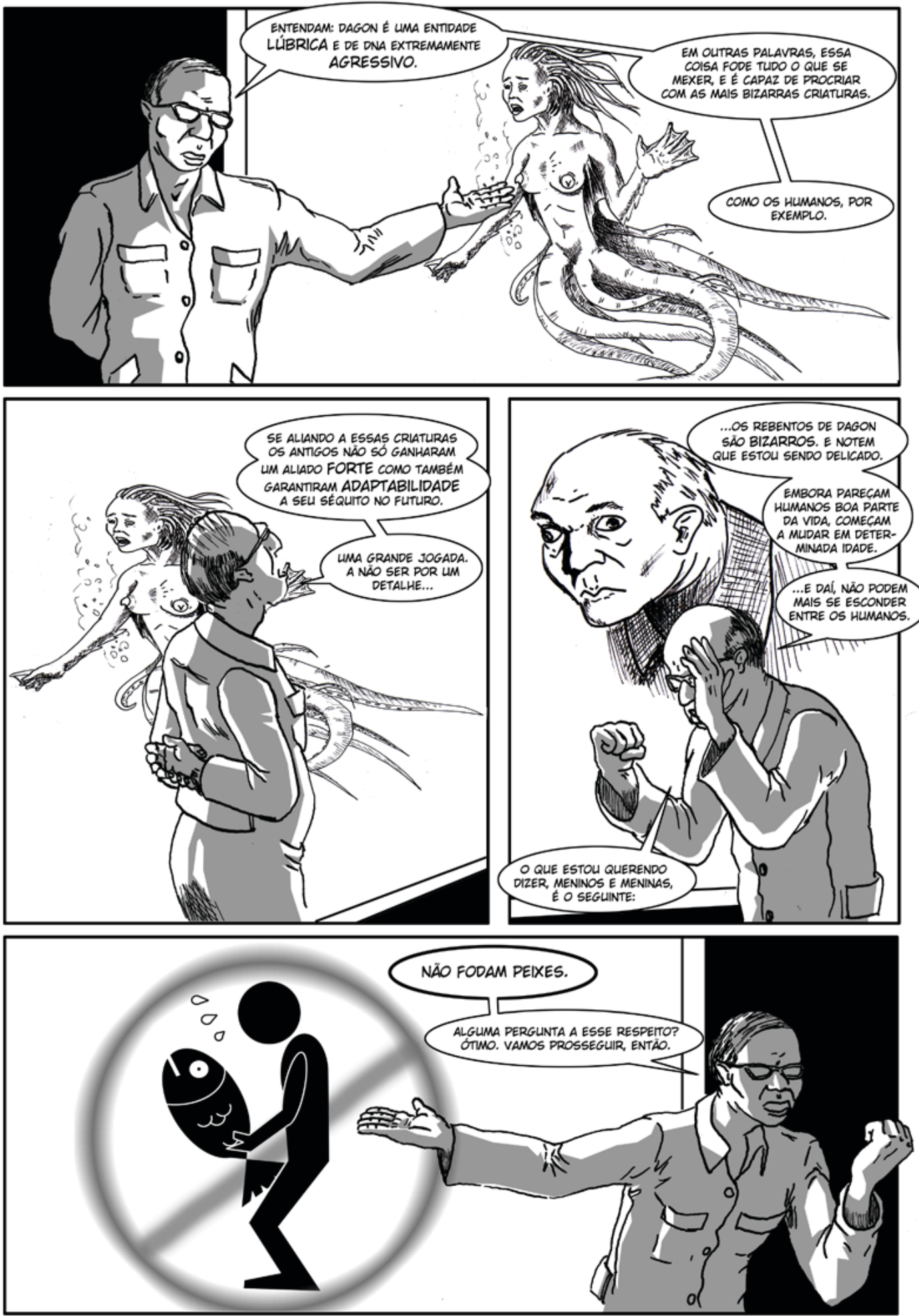

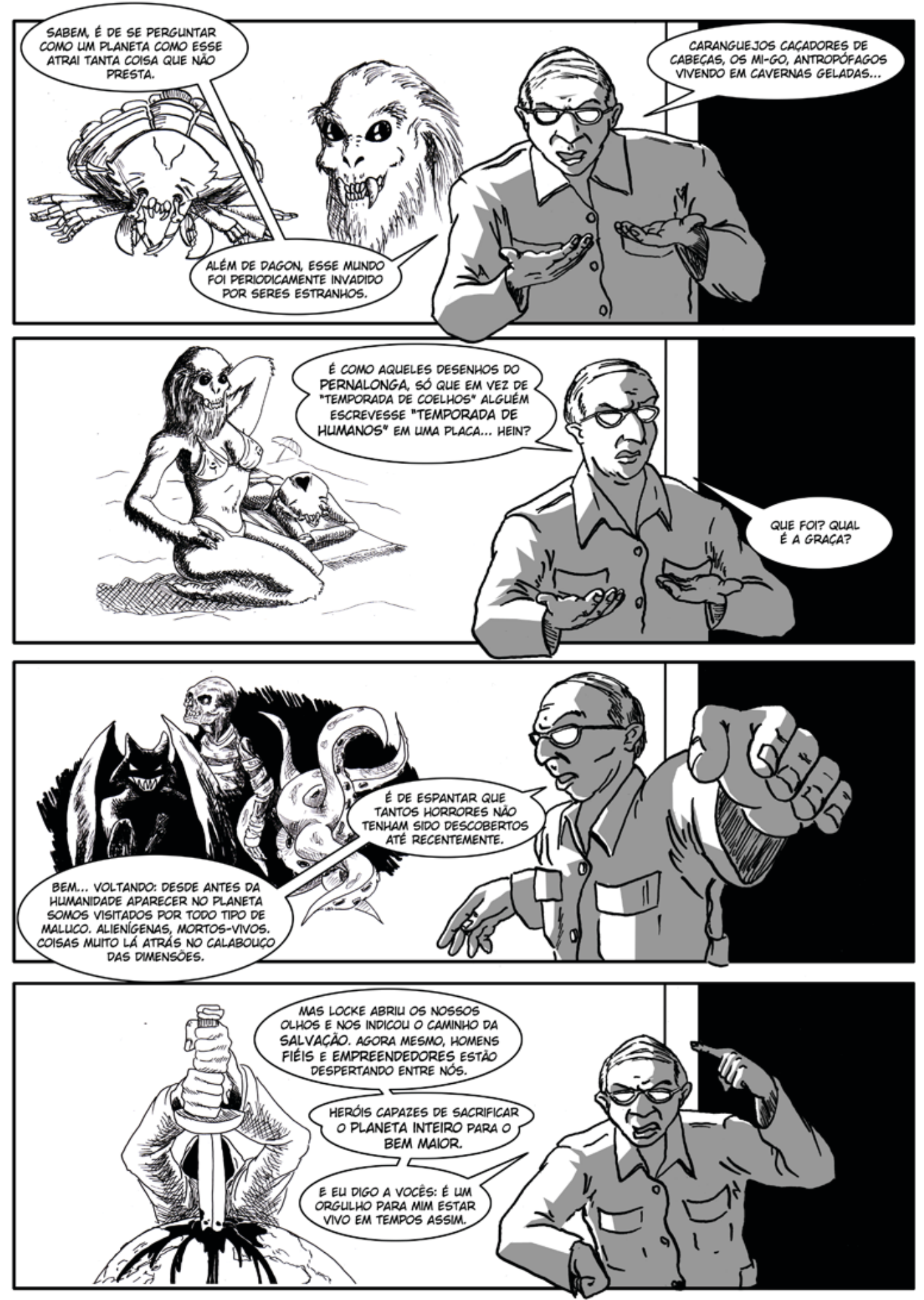


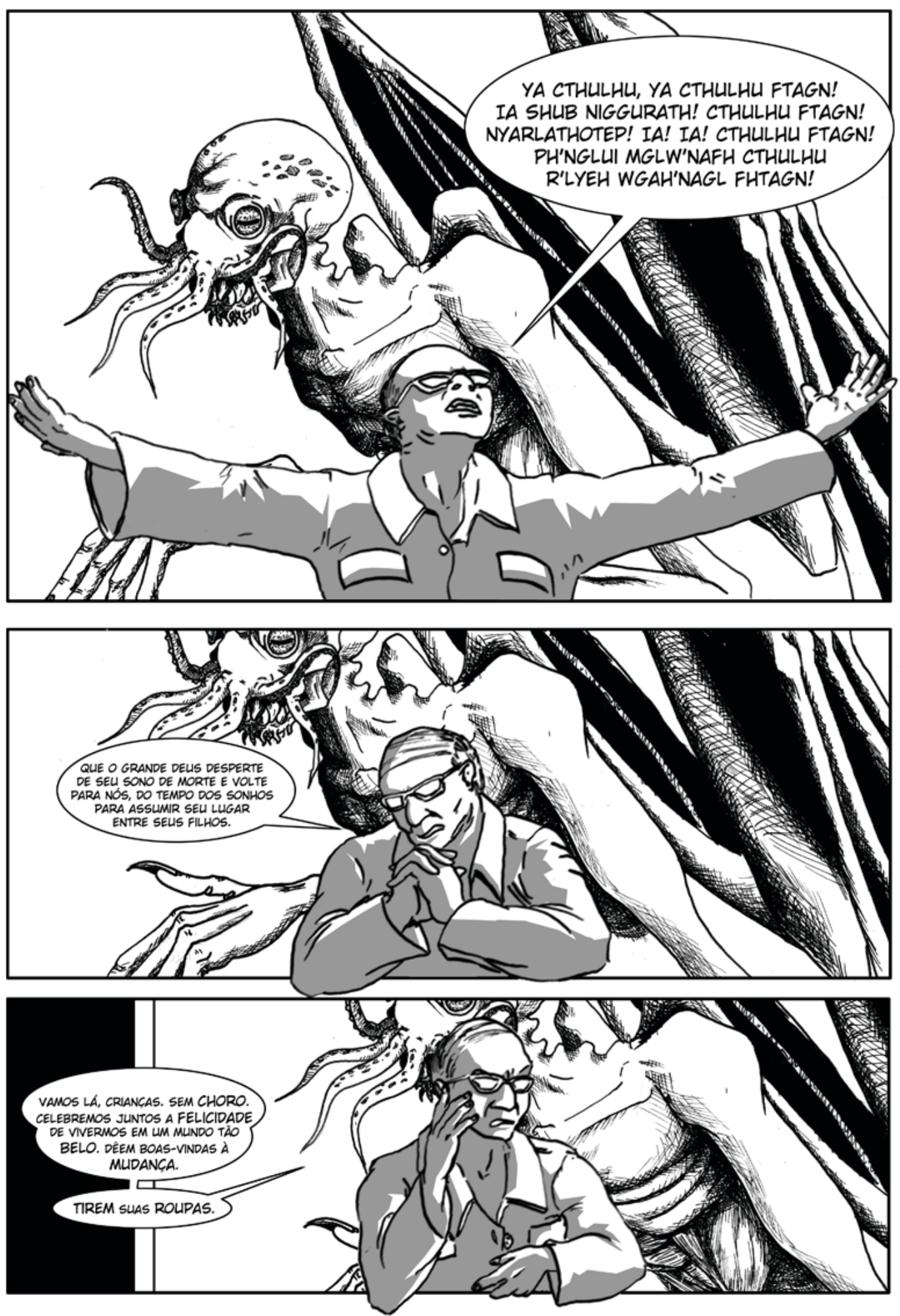
